\title{
Design and Implementation of the Online Computer- Assisted Instruction System based on Object-Oriented Analysis Technology
}

https://doi.org/10.3991/ijet.v13i10.9462

\author{
Wenbo Zhou( $\left.{ }^{\varpi}\right)$, Lei Shi, Jian Chen \\ Institute of Disaster Prevention, Yanjiao Town, China \\ zhouwenbo@cidp.edu.cn
}

\begin{abstract}
The online computer-assisted instruction system has changed the way of knowledge acquisition, and makes knowledge transmission faster, and more convenient and efficient. This study discusses the key technologies of online computer-assisted instruction system with such methods as literature research, system analysis and empirical research, analyzes the requirement of online computer-assisted instruction system with object-oriented analysis method, determines the main functions of online computer-assisted instruction system, and designs the model of online computer-assisted instruction system in detail with the aid of UML technology. The practicality and validity of the model are verified by the realization of some interfaces and processes of the system model.
\end{abstract}

Keywords—constructivism; online; assisted instruction; object-oriented analysis technology; UML

\section{Introduction}

The continuous development of modern information technology provides new possibilities for education and teaching reform while making people acquire knowledge more widely. It's a new modern teaching mode to assist the traditional classroom teaching with modern information technology [1]. Computer assisted instruction is also an important symbol of educational modernization. The rapid development of network provides a new platform for innovation of educational technology, ideas and means, and lays a solid foundation for online assisted instruction.

As early as the mid-1920s, foreign countries began to study instruction programs and machines. In 1958, IBM Company of USA designed the world's first computer instruction system [2], which opened a new era of computer-assisted instruction. With the development of all kinds of theories and technologies, computer-assisted instruction has developed rapidly and popularized from primary school to adult education. More and more companies are dedicated to the $\mathrm{R} \& \mathrm{D}$ and production of industries related to computer-assisted instruction system. The integration of communication technology, Internet technology and computer assisted instruction not only accelerates the 
development of online computer-assisted instruction system, but also changes the traditional concept of teaching and management [3].

The domestic research on computer-assisted instruction started relatively late, but develops rapidly. In the late 1980s, a related society was established [4] and the extensive exchanges were carried out. At the same time, the State attached great importance to this, and increased the policy support for online computer-assisted instruction and related capital investment. The national universities, primary schools and even adult education institutions have carried out related work [5], and has made corresponding results. It can be said that it's the era that the online computer-assisted instruction entered the education field and cause a major change in education.

Based on the above analysis of computer-assisted instruction research and development, in order to enrich the research results of the online computer-assisted instruction system, better realize the educational and guiding functions of the online computerassisted instruction system and meet the needs of teachers and students, this study takes the design and realization of online computer-assisted instruction system as the research objectives, analyzes the function requirement of the online computer-assisted instruction system in detail with object-oriented analysis technology, and then designs the model of the online computer-assisted instruction system based on UML [6]. From the general design, function description and detailed design of the online computer-assisted instruction system, this study finally verifies the practicality of the model by the realization of the system interactive interface and online examination system.

\section{Key Technologies of Online Computer-Assisted Instruction System}

\subsection{Object-oriented analysis and design method}

Object-oriented approach. The object refers to anything studied [7], and the object studied in this paper refers to the objects and entities of the online computer-assisted instruction system, namely students, teachers and courses. The object-oriented technology is to describe the object entity with the object-centered, natural and close-to-reality way in the process of software design, and construct the corresponding system software, which can truthfully reflect the event relationship among objects in the online computer-assisted instruction system, and has the characteristics of encapsulation, polymorphism and inheritance [8].

Unified Modeling Language (UML). Modeling is to solve the complex problems by addressing small problems in the system one by one [9]. Unified Modeling Language (UML) is a general graphical modeling language in object-oriented development. The model elements are used to construct the model of the whole system, which is composed of common mechanism, model element, diagram and view [10]. Figure 1 shows a "4+ 1" view of the structure of a software system. Each view reflects a specific aspect of the system. UML describes the architecture of the software system through these five views. As can be seen from the figure, the view of use case is the core and basis of the whole system. By enumerating roles and use cases, the participation of each role in the 
use case is displayed, and the function that the system should have is described statically [11].

In the system model, diagrams are usually used to describe the contents of each view, and Figure 2 shows the diagrams in UML, including example diagrams describing functions, component diagrams describing physical architectures, and distribution diagrams [12].

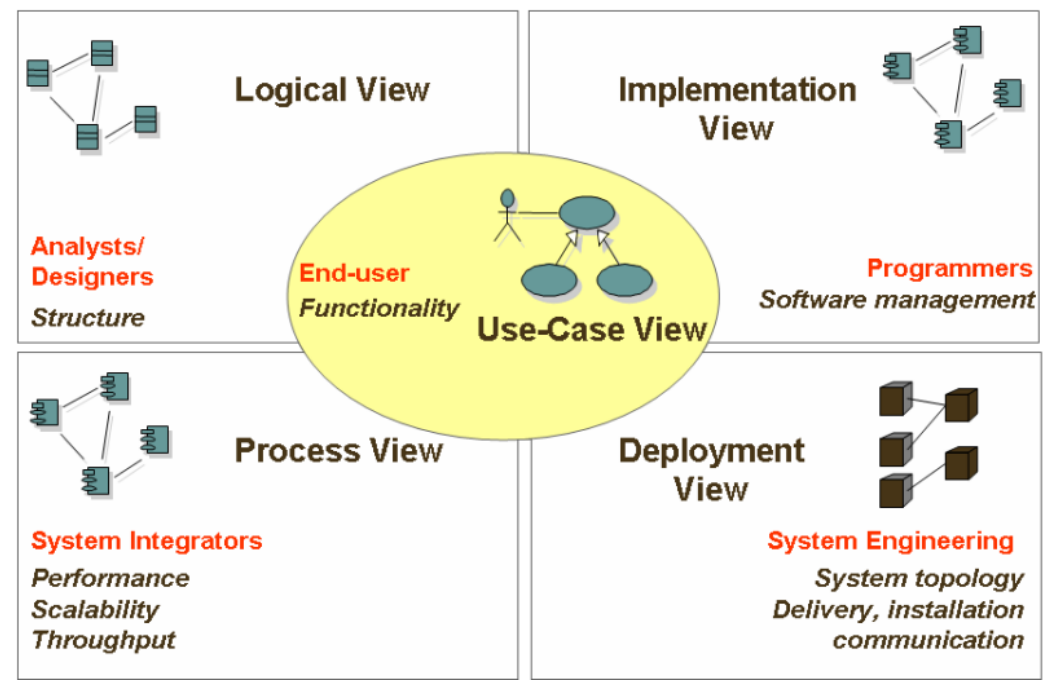

Fig. 1. The "4+1" view of the software system structure

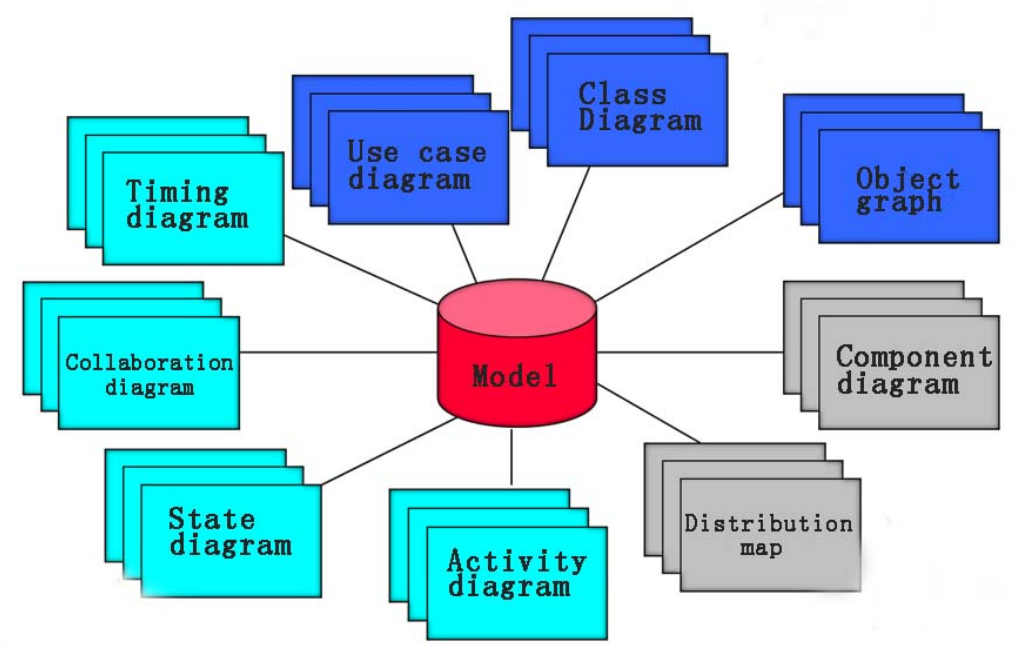

Fig. 2. UML diagram 


\subsection{Computer network and communication technology}

The online computer-assisted instruction system has changed the problem that the traditional teaching mode is limited by the time and place of class, and realized that the students can study at any time and place, which mainly depends on the network technology and the communication technology. All kinds of teaching resources, such as sound and graphics, are exchanged and transmitted in the two-way through the Internet [13]. Figure 3 shows an on-line transmission teaching mode based on the Internet. In order to guarantee the communication quality of the source and the channel, B/S (browser-server) mode is adopted in this study [14].

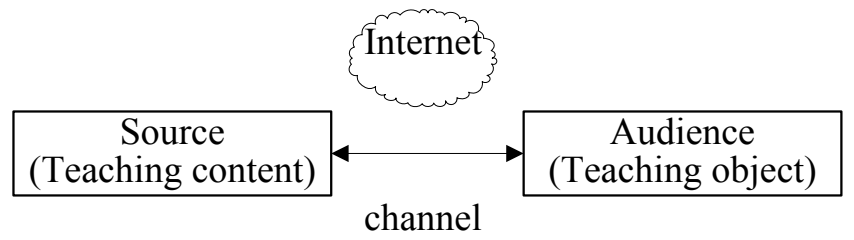

Fig. 3. Internet-based online teaching mode

\section{Design and Implementation of the Online Computer-Assisted Instruction System}

\subsection{System requirement analysis}

System overview. In order to make up for the problems such as limited teaching time and insufficient teaching guidance in traditional classroom teaching, this study makes a detailed analysis of the user demand and function demand of the online computer-assisted instruction system with object-oriented analysis from the point of view of students and teachers. Based on Internet application system, teachers and students can realize functions of the online computer-assisted instruction system through the application servers, database servers and browsers and thus achieve the effective use and management of network teaching resources [15]. For the purpose of providing better learning guidance for students, the system should have the characteristics of rich teaching resources, scientific content form, autonomous learning process, diverse learning strategies, transparent curriculum release, sufficient interaction, and close information monitoring. Figure 4 shows a simple description of the online computer-assisted instruction system. 


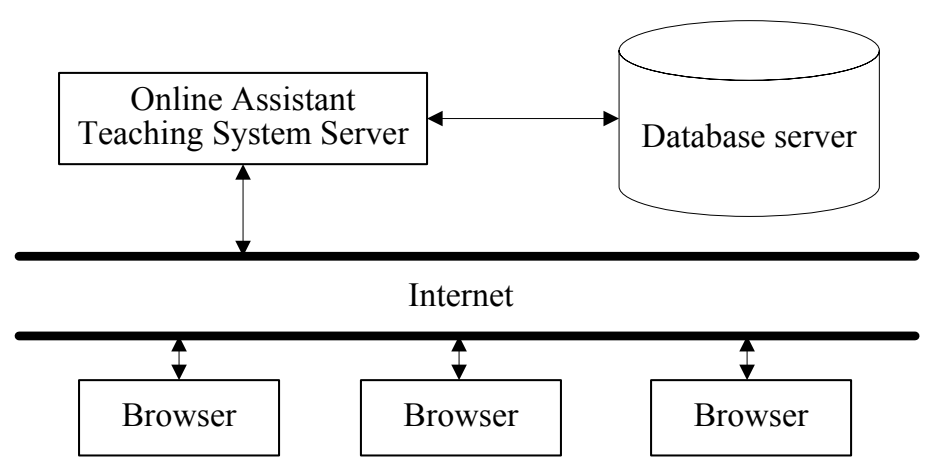

Fig. 4. A simple description of the online assistant teaching system

System function analysis. Through an overview of the system, the main functions of the online computer-assisted instruction system should include [16]:

Login and application. Whether teachers, administrators or students, all have their own secure login mode, and they can log in the system after completing application forms and getting the approval. Different roles may see different interfaces and functions, after logging in the system, for example, students can complete online learning and exchanges, and teachers can release teaching resources and learn about the students' learning dynamics.

Learning function. The learning function is the core function of the computer-assisted instruction system. After the students $\log$ in the system, they directly enter the learning environment, which is different learning situation created by the teachers according to the constructivist theory, and transmits the knowledge points in the course to the students by means of multimedia technology in the form of vivid sound, image, courseware, etc. In such adaptive learning situation, students can acquire knowledge conveniently and quickly, build their own knowledge architecture, and improve their learning efficiency through interactive learning.

Information release function. This function is a bridge connecting the education center and the students. Teachers and administrators can release the learning plans of relevant curriculum, announcements, notices and other contents. The students can understand the basic information of the curriculum, check teachers' relevant guidance on the curriculum, and adjust the learning plans at any time according to the guidance requirements of the teachers.

Interactive function. To construct a place for teachers and students to exchange and study, students can leave messages and discuss in the interactive area according to their own learning comprehension and problems encountered. Teachers or other students can answer the questions after seeing the messages. This not only facilitates the real-time guidance of teachers on students, but also trains the students' ability to analyze and solve problems.

Online examination. The function of online examination includes the management function of examination item bank and the function of online examination and evaluation. Teachers can make test questions on the network and carry out various kinds of tests through the management function of examination item bank. Students can carry 
out online examination and answer items presented by the browser. After students answer the items, the system will automatically score, reducing the workload of teachers.

Online trading. This function is mainly to facilitate the campus teachers and students to deal with idle items, promoting students to enjoy the application of the online computer-assisted instruction system while ensuring green environmental protection.

Analysis of system use cases. Through the above analysis, we can see that the use case diagram is the core of the UML modeling language and an important part of the object-oriented technology. The use case diagram consists of roles and use cases [17]. Table 1 shows a list of roles and related use case events in the online computer-assisted instruction system.

Table 1. Online Computer Aided Instruction System Event Table

\begin{tabular}{|l|l|l|}
\hline \multicolumn{1}{|c|}{ Actor } & \multicolumn{1}{|c|}{ Event } & \multicolumn{1}{c|}{ Purpose } \\
\hline Student & $\begin{array}{l}\text { Browse tutorial } \\
\text { Online discussion } \\
\text { Finish homework } \\
\text { Online exam } \\
\text { Query results } \\
\text { Online trading }\end{array}$ & $\begin{array}{l}\text { Learning Courses } \\
\text { In-depth understanding and knowledge } \\
\text { Further consolidate knowledge } \\
\text { Test knowledge mastery }\end{array}$ \\
\hline Teacher & $\begin{array}{l}\text { Upload tutorial } \\
\text { Online Q \& A } \\
\text { Job processing } \\
\text { Registered results }\end{array}$ & $\begin{array}{l}\text { Use CAI to complete online lectures } \\
\text { Online tutoring for students } \\
\text { Students understand the knowledge } \\
\text { level }\end{array}$ \\
\hline System administrator & $\begin{array}{l}\text { Maintain student information } \\
\text { Maintain teacher information } \\
\text { Maintain course information } \\
\text { Maintain exam information } \\
\text { Maintain registration information }\end{array}$ & Maintain background data \\
\hline
\end{tabular}

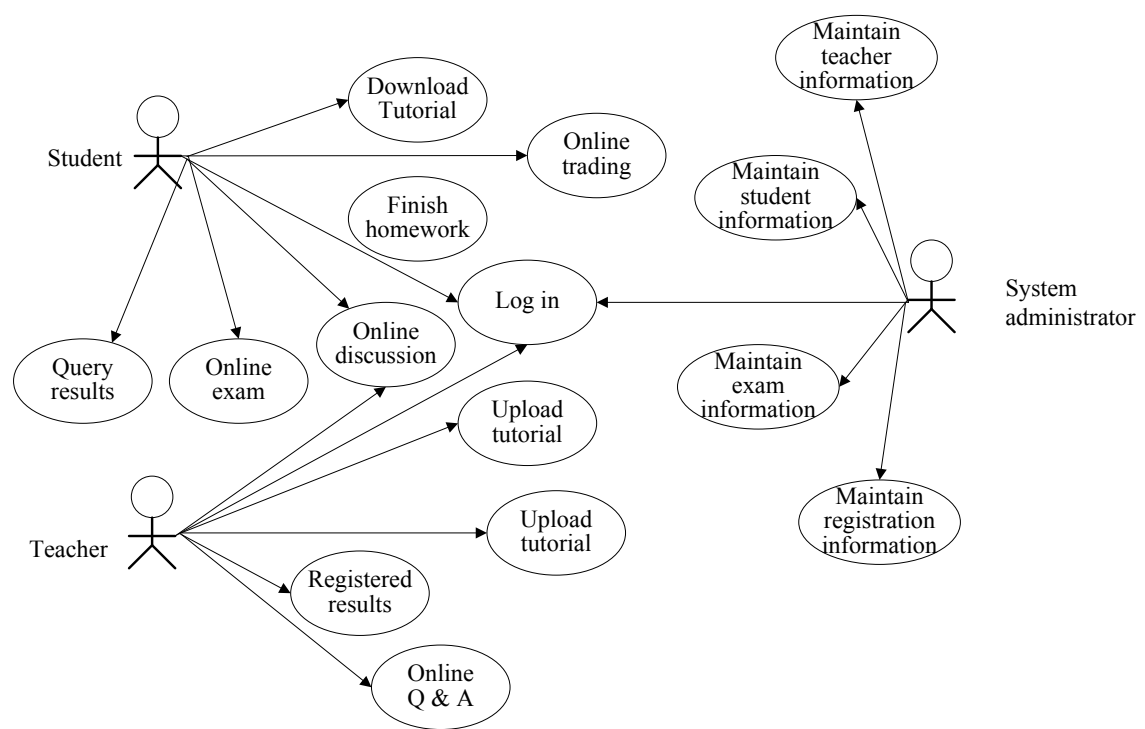

Fig. 5. Online assistive teaching system use case diagram 
According to Table 1, the system uses case model shown in Figure 5 is established. According to different roles and different description of use case events, this study mainly describes the main use case events of teachers and students.

1. Log in: After inputting correct user name and password, the roles can log in the system, and the identity authentication of different roles (students, teachers and administrators) can be realized by logging in.

2. Download tutorials: After the student logs in successfully, they can view the information related to courses and the teachers, selects the online learning or downloads the tutorials uploaded by teachers, and connects the related learning sites.

3. Online discussion and question answering: Online discussion and question answering is an important function to realize the interaction between teachers and students. Students can answer the questions that other students ask him or raise their own questions through online discussion function, or search whether there are the same problems in the past or not through searching function, or discuss the contents with other students in the discussion interface, so as to deepen the understanding and internalization of the knowledge. The system also sets up message board, so that students will write questions on the message board in the absence of teachers, waiting for the teachers' answer. Teachers can also learn about students' learning through online discussions and answer the questions they encounter in a timely manner.

4. Online examination and result inquiry: The online examination can provide the students with the self-test function of knowledge grasping, the students select the section required for test, the system randomly organizes test items, automatically reviews the test when the student answers the items and gives the corresponding score. The final examination can also be carried out with the online test mode. The teachers may, with students' examination paper and results, solve the common questions and send the unified solution to a student's private mailbox through the system, thus answering the questions and solving the puzzle for the students.

5. Course uploading and operation processing: The teachers send content information, teaching plan and assignment of the course to the network through the system, the students can download the relevant information and upload the completed work through the network. The teachers can carry on the corresponding review according to the student's work completion, and then send the work back to the students through the network. 
3.2 General design and function description of the online computer-assisted instruction system

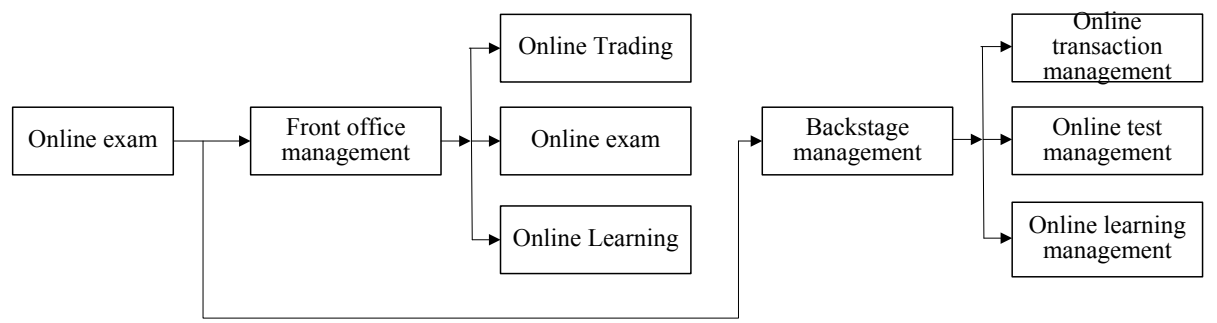

Fig. 6. Online assistant teaching system function module schematic

Figure 6 is a schematic diagram of function modules of the online computer-assisted instruction system designed on the basis of object requirement analysis. The system includes the following three function modules:

1. Online learning: The online learning module is divided into two user modes, namely teachers and students. Only the registrants can enter the system after inputting the corresponding user name and password. Teachers can upload courseware, arrange homework and answer questions on the network after logging in the system, while the students can download the courseware and fulfill online learning functions such as downloading the courseware and completing homework after logging in the system.

2. Online examination: The online examination module includes two types of login interfaces: administrator and examinee. The module can realize the function of automatically organizing test items, judging and multi-user online examination of objective test items, and the examinees with login authority can carry out the online examination anytime and anywhere, obtain the exam result immediately, realize the paperless examination, and reduce the workload of teachers. The specific functions will be described in detail below.

3. Online trading: The online trading module is a second-hand goods trading platform developed for teachers and students. In this module, registered ordinary users can publish the details of their idle goods, browse and query the information of the articles published by others, and make comment and reply on the corresponding articles or problems. The administrator can classify and modify the information related to the second-hand items through the administrator interface, and manage the users and their related comments.

\subsection{Detailed design and implementation of the online computer-assisted instruction system}

Because the space is limited, this paper takes the interactive interface and the online examination system as the example, and carries on the detailed design of the online computer-assisted teaching system. 
Design and implementation of interactive interface. What users need is that the interactive interface designed by the developer can be easily understood. Without reading the user manual, users can determine the functions from the concise icon, text, animation or navigation bar provided by the interface, and enter the corresponding function module by clicking the mouse. Figure 7 shows part of the interface of the online learning system.

Design and implementation of online examination system. According to the user demand, the online examination system module is divided into two interfaces: administrator and student. After the user enters the user name and password in the login interface, the user can log in the corresponding module for operation. Figure 8 is a schematic diagram of the function module of the online examination system designed in this study.

Exam login. As shown in Figure 9, examinees can enter the examination system by inputting the user name and password in the interface, and then clicking the OK key. After the examination is finished, the examinee can submit the examination paper through clicking the OK key. The system will automatically score the examination paper and give corresponding scores, but in the examination process, examinees are not allowed to refresh or exit the exam interface, otherwise the system will automatically consider the exam results as 0 points. When the examinees input error information or the system prompts that the examinee has participated in the exam, the examinee should re-operate.

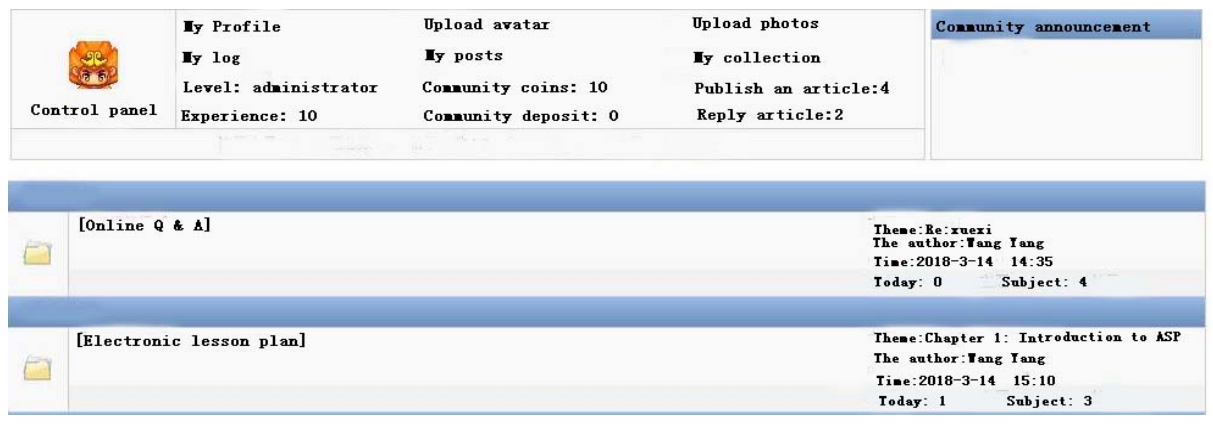

Fig. 7. Online learning system part interface

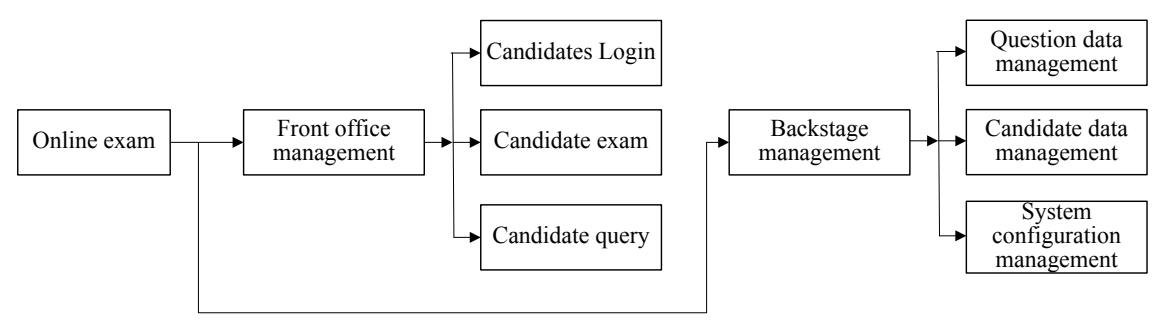

Fig. 8. Online examination system function module diagram 


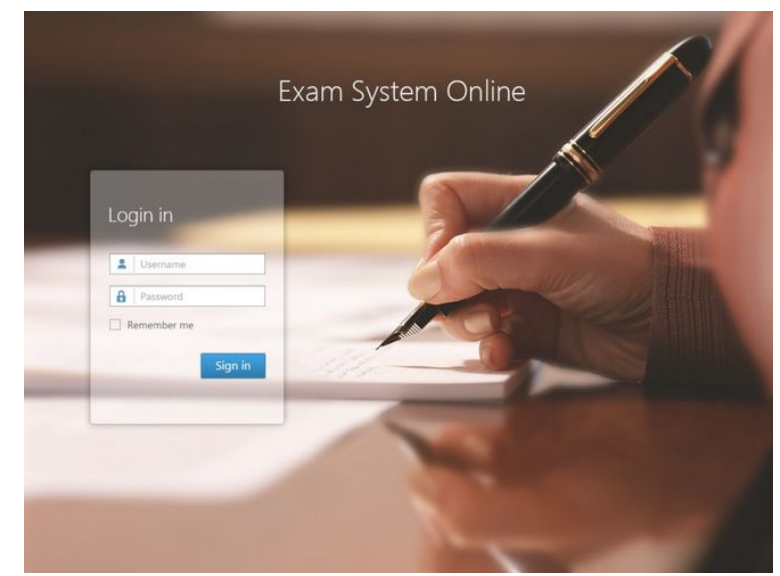

Fig. 9. Candidate login screen

Management module. As shown on the left side of Figure 10, when the administrator inputs the correct user name, password and verification code in the administrator window login interface, the system will automatically jump into the administrator background management interface, and the administrator can select test item data, examinee data and system configuration management as required.

Figure 11 shows a dialog box popped up after clicking on the test item data management module, in which the teachers can browse the test item bank information, add the test item bank data, and build the test item bank table. Figure 12 shows the operation interface presented after clicking on the test item bank information. The teachers can browse, add and delete the information of the item bank in this interface.

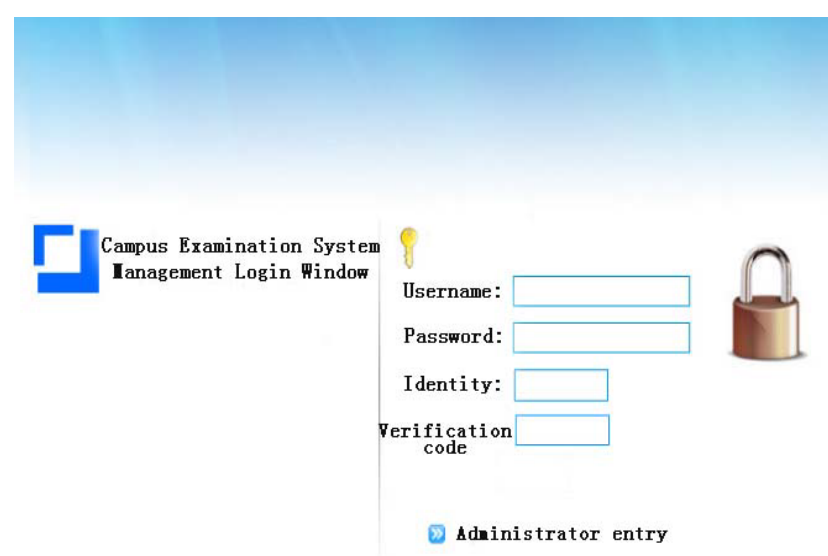

Fig. 10.Management module login and management interface 


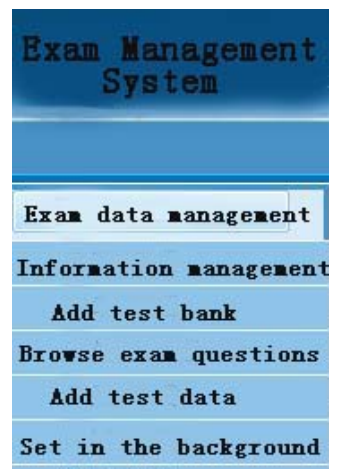

Fig. 11.Questions Data Management

Information browsing
\begin{tabular}{|l|l|l|}
\hline Hunbering & Exanination title & Related operations \\
\hline 1 & Conputer technology & Delete/lodify/Add \\
\hline 2 & vb programing & Delete/Iodify/Add \\
\hline 3 & C language design & Delete/Iodify/Add \\
\hline
\end{tabular}

Fig. 12.Question Information View

\section{Conclusions}

Based on the research of the online computer-assisted instruction technology, this study designs an online computer-assisted instruction system based on object-oriented analysis technology. The detailed work is summarized as follows:

1. Based on the object-oriented method, this study makes a detailed analysis of the user demand and function demand of the online computer-assisted instruction system from the point of view of students and teachers.

2. This study uses UML technology to describe roles and related use case events in the online computer-assisted instruction system, and establishes the system model.

3. This study completes the detailed design and implementation of the interactive interface and on-line examination system in the online computer-assisted instruction system.

\section{$5 \quad$ References}

[1] Blok, H., Oostdam, R., Otter, M.E., Overmaat, M. (2002). Computer-assisted instruc-tion in support of beginning reading instruction: a review. Review of Educational Re-search, 72(1): 101-130. https://doi.org/10.3102/00346543072001101

[2] Sagarra, N., Zapata, G.C. (2008). Blending classroom instruction with online home-work: a study of student perceptions of computer-assisted 12 learning. Recall, 20(2): 208-224. $\underline{\text { https://doi.org/10.1017/S0958344008000621 }}$ 
Paper-Design and Implementation of the Online Computer-Assisted Instruction System based on Obj...

[3] Barron, A.E. (2003). Course management systems and online teaching. Journal of Computing in Higher Education, 15(1): 128-142. https://doi.org/10.1007/BF02940856

[4] Wang, P., Chan, P.S. (1995). Advantages, disadvantages, facilitators, and inhibitors of computer-aided instruction in Singapore's secondary schools. Computers \& Educa-tion, 25(3): 151-162. https://doi.org/10.1016/0360-1315(95)00048-8

[5] Matta, K.F., Kern, G.M. (1989). A framework for research in computer-aided instruc-tion: challenges and opportunities. Computers \& Education, 13(1): 77-84. https://doi.org/10.1016/0360-1315(89)90041-9

[6] Tan, D.P., Ji, S.M., Jin, M.S. (2013). Intelligent computer-aided instruction modeling and a method to optimize study strategies for parallel robot instruction. IEEE Trans-actions on Education, 56(3): 268-273. https://doi.org/10.1109/TE.2012.2212707

[7] Vichitvejpaisal, P., Sitthikongsak, S., Preechakoon, B., Kraiprasit, K., Parakkamodom, S., Manon, C. (2001). Does computer-assisted instruction really help to improve the learning process. Medical Education, 35(10), 983-989. https://doi.org/10.1111/j.13652923.2001.01020.x

[8] Baumlin, K.M., Bessette, M.J., Lewis, C., Richardson, L.D. (2000). Emcyberschool an evaluation of computer-assisted instruction on the internet. Academic Emergency Medicine, 7(8): 959-962. https://doi.org/10.1111/j.1553-2712.2000.tb02083.x

[9] Miller, K., Norton, K., Reeve, R.C., Servant, D.M. (1983). Audio-enhanced computer assisted learning and computer controlled audio-instruction. Computers \& Education, 7(1): 33-54. https://doi.org/10.1016/0360-1315(83)90005-2

[10] Loo, S.K., Freeman, B., Moses, D., Kofod, M. (2009). Fabric of life: the design of a sys-tem for computer-assisted instruction in histology. Medical Teacher, 17(3): 269-276. https://doi.org/10.3109/01421599509008316

[11] Quealy, J., Langan-Fox, J. (1998). Attributes of delivery media in computer-assisted instruction. Ergonomics, 41(3): 257-279. https://doi.org/10.1080/001401398187026

[12] Jones, L.E. (2011). Introducing the icf: the development of an online resource to sup-port learning, teaching and curriculum design. Physiotherapy, 97(1): 55-58. https://doi.org/10.1016/j.physio.2010.10.001

[13] Wong, L.H., Chai, C.S., Zhang, X., King, R.B. (2015). Employing the tpack framework for researcher-teacher co-design of a mobile-assisted seamless language learning envi-ronment. IEEE Transactions on Learning Technologies, 8(1): 31-42. https://doi.org/10.1109/ TLT.2014.2354038

[14] Gorman, M.E., Richards, L.G., Scherer, W.T., Kagiwada, J.K. (1995). Teaching inven-tion and design: multi-disciplinary learning modules. Journal of Engineering Educa-tion, 84(2): 175-185. https://doi.org/10.1002/j.2168-9830.1995.tb00164.x

[15] Özyurt, Ö., Özyurt, H., Baki, A. (2013). Design and development of an innovative in-dividualized adaptive and intelligent e-learning system for teaching-learning of prob-ability unit: details of uzwebmat. Expert Systems with Applications, 40(8): 2914-2940. https://doi.org/10.1016/j.eswa.2012.12.008

[16] Plessis, J.P.D., Biljon, J.A.V., Tolmie, C.J., Wollinger, T. (1995). A model for intelli-gent computer-aided education systems. Computers \& Education, 24(2): 89-106. https://doi.org/10.1016/0360-1315(95)00001-3

[17] Hwang, G.J. (2003). A conceptual map model for developing intelligent tutoring sys-tems. Computers \& Education, 40(3): 217-235. https://doi.org/10.1016/S0360-1315(02)00121-5 


\section{Authors}

Wenbo Zhou graduated from North China Electric Power University in 2002 with a bachelor's degree in computer science and technology. He graduated from Renmin University of China in 2010 with a master's degree in computer application technology. His main research directions include the construction of intelligent campus and the construction of educational informatization.

Lei Shi graduated from Communication University of China with a master's degree in electronics and communication engineering. His main research direction is the construction of information security system.

Jian Chen graduated from Renmin University of China with a master's degree in computer application technology. His main research direction is the construction of the intelligent teaching system.

Article submitted 12 July 2018. Resubmitted 29 July 2018. Final acceptance 13 August 2018. Final version published as submitted by the authors. 